\title{
Pathogenesis of experimental bovine spongiform encephalopathy (BSE): estimation of tissue infectivity according to incubation period ${ }^{\S}$
}

\author{
Mark Edward ARNOLD*, Stephen Anthony Charles Hawkins, Robert GreEn, \\ Ian DeXTER, Gerald Arthur Henry Wells
}

Veterinary Laboratories Agency, Woodham Lane, New Haw, Addlestone, Surrey, KT15 3NB, United Kingdom

(Received 6 May 2008; accepted 23 October 2008)

\begin{abstract}
This paper reports the results of tissue infectivity assays of bovine spongiform encephalopathy (BSE) agent in orally exposed cattle at stages during the incubation period. Estimations of the titre of infectivity in central nervous system (CNS), certain peripheral nerve ganglia and distal ileum tissue were made according to time post exposure from the relationship between incubation period and dose for RIII mice and C57bl mice using data from titrations of brain material from cases of BSE. The rate of increase of infectivity in the bovine CNS was then estimated, taking into account these tissue infectivity titres, the variability of the brain titre of clinical field cases of BSE, and the probability density of the expected number of months before clinical onset of each infected bovine. The doubling time for CNS was shown to equal 1.2 months. The titre in the thoracic dorsal root ganglia (DRG) was, on average, approximately 1 log units less than CNS, and cervical DRG approximately 0.5 log less than thoracic DRG. The pattern of increase of infectivity in the distal ileum is that of an initial increase up to 14-18 months post exposure, followed by a decrease, which is likely to be highly variable between animals. These results will be informative for future risk assessments of BSE, especially in relation to reviewing current control measures.
\end{abstract}

bovine spongiform encephalopathy / pathogenesis / modeling / infectivity titres / maximum likelihood estimation

\section{INTRODUCTION}

Results of oral exposure studies of the pathogenesis of bovine spongiform encephalopathy (BSE) in cattle, conducted in the United Kingdom, have been reported previously $[1,13,25,29-34]$. The initial study $[32,34]$ examined the distribution of infected tissues in cattle exposed as calves to $100 \mathrm{~g}$ of BSE infected brainstem and killed at intervals throughout the course of the disease. Tissues were collected at each kill time point

$\S$ This article is subject to British Crown copyright. * Corresponding author: m.arnold@vla.defra.gsi. gov.uk post exposure (p.e.) for bioassay, initially, in inbred mice. Previous reports of the study have recorded infectivity detected by mouse bioassay in the distal ileum (6-18 months and 36-40 months p.e.) and in the central nervous system (CNS) (32-40 months p.e.); the earliest onset of definite clinical signs in the cattle occurring at 35 months p.e. [32]. Infectivity was also detected in certain sensory ganglia of the peripheral nervous system (32-40 months p.e.) and traces of infectivity were also shown in sternal bone marrow, but only from cattle killed 38 months p.e. [33].

Data from this oral exposure study were used to tentatively classify certain tissues as being of high, medium or low infectivity at 
certain time periods post exposure ${ }^{1}$. However, models of the BSE epidemic $[8,14,15,20]$ and assessments of the human risk of exposure to the BSE agent $[4,5,12,18]$ require quantitative estimates of the infectivity by stage of incubation period and the data required to produce such estimates have not previously been available. Although the BSE epidemic has declined to a very low prevalence [11] such quantitative estimates remain of interest as they are important in risk assessments of the impact of potential human exposure on relaxing BSE control measures.

The objective of this paper is to report the completed results of the wild-type mouse assays of infectivity of CNS, certain peripheral nerve ganglia and distal ileum tissues taken throughout the course of the initial UK oral exposure study of experimental BSE in cattle and to estimate the infectivity in these tissues according to incubation period. Of particular interest is the rate of increase of infectivity, or doubling time, in CNS which has a large impact on estimates of potential human exposure in terms of bovine oral $\mathrm{ID}_{50} \mathrm{~s}[5,16]$ and in the dorsal root ganglia (DRG), which have been estimated to have made the largest contribution to human exposure to BSE in contaminated products since the implementation of specified bovine offal legislation in the early 1990s [5]. Also of interest is the pattern of infectivity in distal ileum over the course of the incubation period, since it could have important implications for the pathogenesis of BSE in cattle.

\footnotetext{
${ }^{1}$ European Commission, Scientific Steering Committee Update of the Opinion on TSE Infectivity distribution in ruminant tissues (Initially adopted by the Scientific Steering Committee at its meeting of 10-11 January 2002 and amended at its meeting of 7-8 November 2002) following the submission of (1) a risk assessment by the German Federal Ministry of Consumer Protection, food and Agriculture and (2) new scientific evidence regarding BSE infectivity distribution in tonsils, 2002, http://europa.eu.int/comm/food/fs/sc/ssc/outcome_ en.html\#opinions.
}

\section{MATERIALS AND METHODS}

\subsection{Experimental design of the cattle oral exposure pathogenesis study}

The study design has been described previously [31]. Briefly, forty Friesian/Holstein calves, born in 1991, were assembled from farms with no history of BSE. At 4 months of age, 30 were each dosed orally with $100 \mathrm{~g}$ of homogenized pooled brain stems obtained from 75 cases of BSE from various locations in England and Wales, slaughtered in 1991 and confirmed by histopathological examination. An end point titration of infectivity in the pooled brainstem homogenate in RIII mice gave a value of $10^{3.5}$ intracerebral (i.c.)/intraperitoneal (i.p.), mouse $\mathrm{ID}_{50}$ unit/g of tissue [22]. Ten calves received no treatment and served as controls. Clinical monitoring of cattle was maintained throughout the period of study to detect the onset of clinical signs consistent with BSE. Exposed and control cattle were killed sequentially starting at six months of age (Fig. 1).

A large range of tissues were sampled aseptically at each sequential kill time point for infectivity assays in inbred mice [31].

\subsection{Mouse bioassay of cattle tissue infectivity}

Inocula were prepared as previously described [32] from a total of 52 tissues, representing principally the lymphoreticular system, the peripheral nervous system, the CNS, alimentary tract, striated muscles and major viscera (see supplementary material available online only, Tab. IS). All inocula were prepared as ten per cent suspensions in saline, with the inclusion of antibiotics for certain tissues. Single tissue inoculum pools were made from the exposed cattle at each time point. Control inocula were similarly prepared but from single tissues of each control animal.

Test and control tissue inocula were each assayed in 20 RIII, and/or C57bl inbred mice according to standard procedures. Each mouse was injected with $0.02 \mathrm{~mL}$ by the i.c. route and $0.1 \mathrm{~mL}$ by the i.p. route. Detailed clinical monitoring of the mice was carried out from 250 days postinoculation (p.i.) and the clinical end point when mice show clear signs of neurological disease was determined according to established criteria for calculating incubation period [9]. The brain of each mouse was removed, fixed in $10 \%$ phosphate 


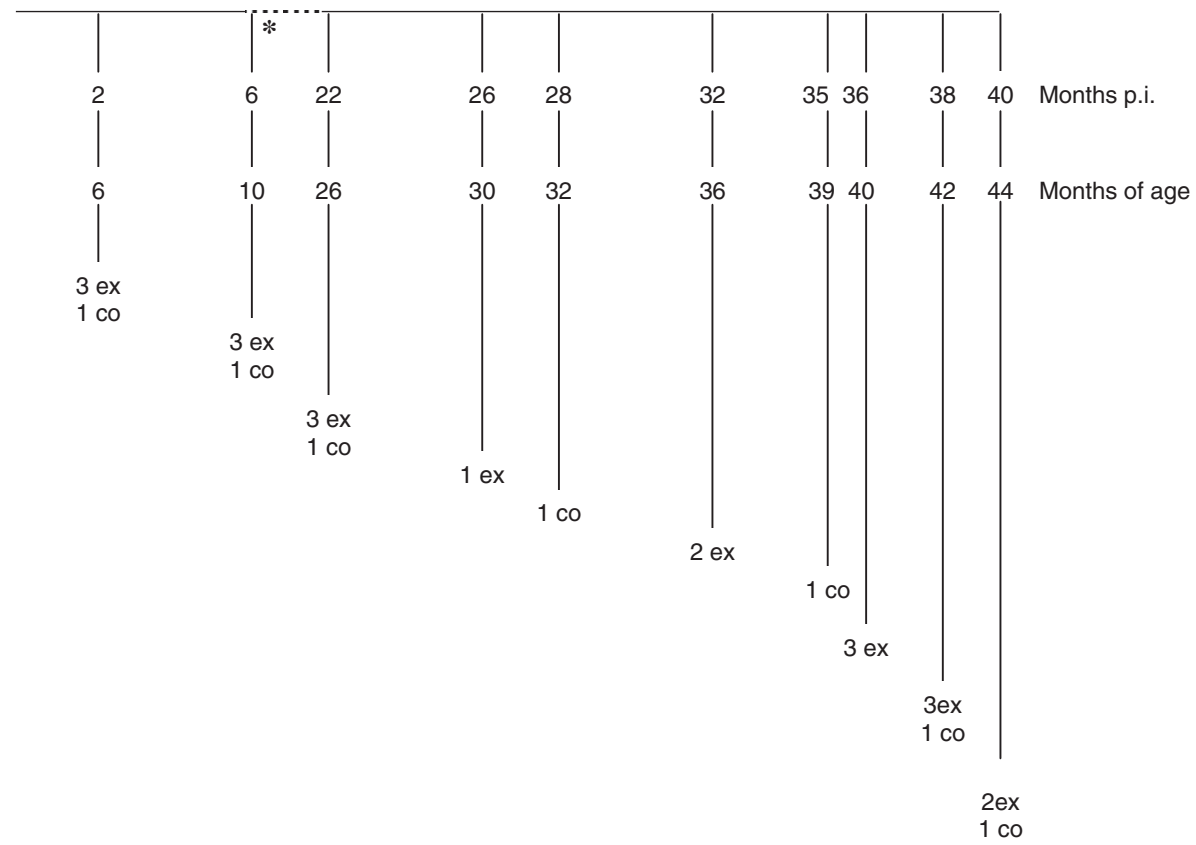

Figure 1. Schedule of sequential kill time points of exposed and control cattle.

* Kills continuing at 4 month intervals to 22 months p.i.; ex: exposed; co: control.

buffered formalin $(\mathrm{BF})$, and processed routinely for histopathological examination for evidence of spongiform encephalopathy. Any mice surviving to the end point for incubation and expression of the disease were killed and examined similarly, as were any mice that died or were killed due to intercurrent disease. Previously determined assay end points of 650 days, (occasionally, depending on tissue, extended to 700 days) for RIII mice and 950 days for C57bl mice defined the termination of the assays.

\subsection{Estimation of titres from incubation period assay}

Bioassay, using endpoint titration, is regarded to be the most accurate method for the determination of the concentration of infectivity of transmissible spongiform encephalopathy agents in tissue. Estimation of infectivity by end-point titration in mice of tissues of cattle with BSE has been limited to the study of CNS in terminal cases and there are as yet no data on titration of any tissue at various stages of incubation. Although regarded as less accurate, dose-response relationships have been used as a method for infectivity estimation $[10,26]$ when endpoint titration data are not available. In this study, we adopt a method that is similar in principle to incubation period assay $[10,26]$ but also takes into account the proportion of mice which become clinical, providing a more accurate estimate of titre at lower doses than solely using the mean incubation period. To derive the dose/incubation relationship to be used to convert the incubation periods from the RIII mouse bioassay into titres of infectivity, data were analysed from titrations in RIII mice of several different pools of brain material (whole brain or brain stem) from clinical field cases of BSE (see supplementary material available online only, Fig. 1S). The method is then as follows.

There are two potential outcomes for each mouse; either it could become clinical at $t$ months post-inoculation, with probability $P_{c}(t)$, or it could die due to causes unrelated to BSE (through intercurrent disease or be sacrificed at the experimental end point), with probability $P_{S}(t)$. Denoting the titre of inoculum to which the individual mouse was exposed by $\omega$, and denoting the dose-dependent probability of infection and incubation period (IP) by $S(\omega), f(\omega)$ respectively 
these outcomes are given by:

$$
\begin{gathered}
P_{C}(t)=S(\omega) f(\omega) \\
P_{S}(t)=S(\omega) \int_{t}^{\infty} f(\omega) d t^{\prime}+(1-S(\omega))
\end{gathered}
$$

The log-likelihood of the observed mouse IP data from tissue $i$ taken from a bovine at $T$ months p.e. is then given by:

$$
\sum_{j=1}^{N_{i, T}^{+}} \log \left(P_{c}\left(t_{j}\right)\right)+\sum_{j=1}^{N_{i, T}^{-}} \log \left(P_{S}\left(t_{j}\right)\right)
$$

where $N_{i, T}^{+}, N_{i, T}^{-}$were the number of mice which became clinical and the number of mice which die without showing clinical signs respectively for tissue $i$ taken from cattle at $T$ months p.e., and $t_{j}$ is the IP of the $j$ th mouse. Estimates of the titre for each positive tissue for each time point are obtained by maximising the log-likelihood given in equation (3).

\subsection{Estimation of rate of increase of the titre of infectivity in bovine CNS}

An exponential increase with constant rate has been observed experimentally in scrapie infected hamsters $[2,7]$ for prion protein and titre of infectivity in the CNS tissues as time p.i. increased. It has also been assumed in modelling and risk assessments that the titre of infectivity increases according to an exponential with constant rate in BSE in cattle $[4,5,8,19,20]$. The assumption is also made in this study and corresponds to a linear increase in the log titres of infectivity as time post infection increases, or, in terms of clinical onset, a linear decrease in the log titres of infectivity in CNS as time before clinical onset increased, i.e.

$$
d(\tau)=d(0)-\alpha \tau
$$

where $d(\tau), d(0)$ represent the titre of infectivity in the CNS at $\tau$ months before and at clinical onset respectively, and $\alpha$ is the growth rate of the titre of infectivity.

It was assumed that $\alpha$ is the same in each of the different parts of the CNS.

While the estimates of titre by time point from the $100 \mathrm{~g}$ dosed cattle are useful for investigations of the pathogenesis of BSE and for gaining an understanding of the relative infectiousness of different tissues, they have only limited applicability to field cases since the majority of which had much longer incubation periods, reflecting lower exposures [1]. Therefore, it is useful for risk assessment purposes to have the estimate of titre in terms of the number of months before clinical onset, as this will correct for differences in the incubation period distribution between the $100 \mathrm{~g}$ dosed animals and low exposures in field cases. It also enables the use of the knowledge of the titre of infectivity at clinical onset in field cases (given below). Although the number of months before onset for the sub-clinical cattle in a sequential kill study cannot be determined, the results from an oral attack rate study [35] provide the incubation period distribution of cattle given a $100 \mathrm{~g}$ dose and hence the probability density of the number of months before clinical onset (a lognormal distribution with parameters $\mu=3.78$, $\sigma=0.20$ with left truncation at the age of culling). Therefore the likelihood of the RIII mouse bioassay data was calculated by integrating over all possible values of the number of months before clinical onset for the cattle from which the bio-assayed tissues were taken:

$$
\begin{aligned}
P_{C}(t)= & \int_{0}^{\infty} S(\omega) f(t, \omega) \frac{\hat{f}(T+\tau)}{1-\hat{F}(T)} d \tau \\
P_{S}(t)= & \int_{0}^{\infty}\left[S(\omega)\left(\int_{t}^{\infty} f\left(t^{\prime}, \omega\right) d t^{\prime}\right)+(1-S(\omega))\right] \\
& \times \frac{\hat{f}(T+\tau)}{1-\hat{F}(T)} d \tau
\end{aligned}
$$

where $S, f, \omega$ are as in equations (1) and (2), $\tau$ is the number of months before clinical onset of the cattle from which the tissue was taken, $\hat{f}$ is the probability density function of the cattle incubation period given the $100 \mathrm{~g}$ oral dose, and $\hat{F}$ is the cumulative distribution function of the cattle incubation period. The $(1-\hat{F})$ term in the denominator accounts for the left truncation of the incubation period (since the incubation period could not be shorter than the culling age of the cattle as cattle were culled if they reached clinical onset).

From titrations conducted in mice on brain from clinical or clinical suspect cases of BSE (at VLA or at the former Neuropathogenesis Unit, Institute of Animal Health, Edinburgh), a wide range of 
titres have been obtained: $10^{2.4}-10^{5.2}$ mouse i.c. or i.c./i.p. $\mathrm{ID}_{50} / \mathrm{g}^{2,3}[17,24,28]$. These data were used to estimate the titre at clinical onset and its variability. From this, the mean titre of brain at clinical onset was given by 3.3 , with standard deviation of 0.58 . The log-likelihood of the data was then given as in equation (1) but with an additional step of integrating over all possible values of the clinical titre.

The rate of increase of infectivity, $\alpha$, was found by maximising the log-likelihood of the mouse bioassay data (1) for the caudal medulla and spinal cord tissues, consisting of four data points at each of the four time points selected. The frontal cortex was omitted as the 40 month time point was the only one for this tissue where the titre could be estimated with sufficient precision.

The variability of the titre at a given number of months p.e. was explored by taking 10000 random draws from the incubation period distribution for the $100 \mathrm{~g}$ dose (using the bovine doseresponse relationship estimated previously [35], 10000 random draws from the clinical titre distribution, and calculating the resulting titre using the estimated rate of increase of infectivity in CNS. The fit of the exponential increase model was checked by comparing the expected number of infected mice of each strain at each time point with the observed for each of the four CNS tissues.

\subsection{The titre of infectivity in dorsal root ganglia}

The data on mouse bioassay of DRG were used to investigate how the infectivity in the DRG varies through the incubation period relative to the CNS. The relative timing of detectable infectivity relative to clinical onset for the dorsal root ganglia has been investigated in [1]. This showed that there were differences in the timing of detectable infectivity between the dorsal and cervical DRG, suggesting that the titres of infectivity could differ between them. Therefore, the titre of infectivity was estimated separately for the dorsal and cervical DRG, and since there were limited data, the titre was estimated separately for each part of the DRG for each time point, rather than a trend estimated. The titres were estimated in terms of time p.e. so that equations (1) and (2) were used for the log-likelihood.

${ }^{2}$ Wells G.A.H., Hawkins S.A.C., unpublished.

${ }^{3}$ Bruce M., Taylor D.M., personal communication.

\subsection{The titre of infectivity in distal ileum}

Estimates of the rate of increase of infectivity were attempted from the data on distal ileum at different time points p.e. in the cattle study. It has been reported previously that in the experimental oral exposure of cattle, infectivity in the distal ileum was detected at $6,10,14,18,36,38$ and 40 months but not at 32 months p.e. ${ }^{1}$ and from 6-14 months p.e. infectivity showed a rising titre as indicated by decreasing mean incubation periods in the assay mice $[30,31]$. There are no data on infectivity in distal ileum for the kill time points 22 and 26 months post exposure for RIII mice, and it is therefore uncertain how the titre of infectivity in the distal ileum might vary over the full range of the incubation period. Since the infectivity in distal ileum appears to peak far before clinical onset the estimates were produced in terms of months post exposure rather than months before clinical onset.

The estimates of titre in the distal ileum were obtained using the method of Section 2.3, and the same RIII mouse dose-response curve as was used for the CNS tissues.

\section{RESULTS}

The results of the RIII and C57bl mouse bioassays for which there was at least one positive mouse are given in Table I.

The IP data for the C57bl mice were highly variable and many of the individual IPs were outside the range recorded in the available titration data of brain homogenate in C57bl mice, and so only the data on the number of positive mice were used which correlated closely with the number of RIII mice positive. All other tissues were negative at all time points, with the exception of bone marrow, which was positive at 38 months p.e. only [33].

The upper $95 \%$ confidence interval of the maximum titre consistent with the data for the negative tissues varied according to the mean survival time of the mice inoculated with the respective tissue; the power of the study is lessened by intercurrent death. From the RIII data the negative tissue assayed for which there was the lowest mean survival time in the mice was the trigeminal ganglia at 32 months p.e., with a mean survival time of 237 days and 4 mice surviving to end point; the upper $95 \%$ confidence interval for 
Table I. Survival data and mean incubation periods of RIII and C57bl mice inoculated i.c./i.p. with tissues pooled from cattle at time intervals after the cattle were orally dosed with $100 \mathrm{~g}$ of BSE affected brain stem homogenate [32]. Data for tissues and time intervals where transmissions were negative are omitted.

\begin{tabular}{|c|c|c|c|c|c|}
\hline \multirow[t]{2}{*}{ Tissue } & \multirow{2}{*}{$\begin{array}{l}\text { Time post } \\
\text { exposure } \\
\text { (months) }\end{array}$} & \multicolumn{2}{|c|}{ RIII } & \multicolumn{2}{|c|}{ C57bl } \\
\hline & & $\begin{array}{l}\text { No. of mice } \\
\text { +ve/No. of } \\
\text { mice surviving } \\
\text { when first } \\
\text { mouse } \\
\text { confirmed +ve }\end{array}$ & $\begin{array}{c}\text { Mean } \\
\text { incubation } \\
\text { period (days) } \\
(\text { SEM) }\end{array}$ & $\begin{array}{l}\text { No. of mice } \\
\text { +ve/No. of } \\
\text { mice surviving } \\
\text { when first } \\
\text { mouse } \\
\text { confirmed +ve }\end{array}$ & $\begin{array}{c}\text { Mean } \\
\text { incubation } \\
\text { period (days) } \\
\quad(\text { SEM) }\end{array}$ \\
\hline \multirow[t]{7}{*}{ Distal ileum } & 6 & $10 / 12$ & $523.7(17.5)$ & - & - \\
\hline & 10 & $14 / 17$ & $511.4(15.2)$ & - & - \\
\hline & 14 & $15 / 18$ & $455.0(12.8)$ & - & - \\
\hline & 18 & $18 / 18$ & $470.7(12.3)$ & - & - \\
\hline & 36 & $0 / 10$ & N/A & $1 / 2$ & $942.0(-)$ \\
\hline & 38 & $4 / 14$ & $581.5(33.2)$ & $4 / 12$ & $791.3(48.8)$ \\
\hline & 40 & $14 / 17$ & $538.2(16.9)$ & $8 / 19$ & $644.4(32.8)$ \\
\hline \multirow[t]{4}{*}{ Caudal medulla } & 32 & $6 / 17$ & $584.9(24.9)$ & $7 / 16$ & $743(33.4)$ \\
\hline & 36 & $7 / 14$ & $554.9(19.2)$ & $12 / 19$ & $707(24.2)$ \\
\hline & 38 & $14 / 18$ & $486.9(18.1)$ & $14 / 19$ & $608.3(37.2)$ \\
\hline & 40 & $11 / 12$ & $485.0(12.8)$ & $14 / 20$ & $637.5(34.7)$ \\
\hline \multirow[t]{4}{*}{ Cervical spinal cord $\left(\mathrm{C}_{2-3}\right)$} & 32 & $2 / 16$ & $596.0(57.0)$ & $6 / 20$ & $840.8(38.7)$ \\
\hline & 36 & $5 / 13$ & $565.4(28.3)$ & $7 / 14$ & $733.9(19)$ \\
\hline & 38 & $10 / 17$ & $555.1(18.7)$ & $9 / 19$ & $675.4(24.5)$ \\
\hline & 40 & $16 / 20$ & $477.6(10.8)$ & $11 / 16$ & $687.1(27.7)$ \\
\hline \multirow[t]{4}{*}{ Thoracic spinal cord $\left(\mathrm{T}_{10-11}\right)$} & 32 & $2 / 15$ & $523.0(74.0)$ & $8 / 19$ & $787.4(44.1)$ \\
\hline & 36 & $15 / 19$ & $554.5(13.8)$ & $13 / 18$ & $716.2(21.7)$ \\
\hline & 38 & $8 / 17$ & $576.2(15.6)$ & $6 / 19$ & $703.2(52.4)$ \\
\hline & 40 & $13 / 18$ & $457.5(11.7)$ & $14 / 19$ & $627.6(25.4)$ \\
\hline \multirow[t]{4}{*}{ Lumbar spinal cord $\left(\mathrm{L}_{3-4}\right)$} & 32 & $3 / 15$ & $570.0(39.8)$ & $9 / 19$ & $730.6(32.8)$ \\
\hline & 36 & $9 / 15$ & $523.7(15.2)$ & $11 / 19$ & $670.8(28.9)$ \\
\hline & 38 & $13 / 16$ & $526.2(16.2)$ & $15 / 20$ & $659.7(25.7)$ \\
\hline & 40 & $16 / 18$ & $485.5(13.7)$ & $11 / 17$ & $666.3(32.5)$ \\
\hline \multirow[t]{3}{*}{ Frontal cortex } & 36 & $1 / 12$ & $552.0(-)$ & $0 / 4$ & N/A \\
\hline & 38 & $1 / 10$ & $642.0(-)$ & $2 / 18$ & 690.5 (135.5) \\
\hline & 40 & $10 / 14$ & $568.0(18.5)$ & $7 / 14$ & $837.3(38.3)$ \\
\hline \multirow[t]{4}{*}{ Thoracic DRG $\left(\mathrm{T}_{5-8}\right)$} & 32 & $3 / 18$ & $541.7(42.8)$ & $3 / 10$ & $807.3(38.4)$ \\
\hline & 36 & $8 / 20$ & $531.9(25.1)$ & $9 / 18$ & $654.4(22.5)$ \\
\hline & 38 & $0 / 7$ & N/A & $1 / 18$ & $614.0(-)$ \\
\hline & 40 & $9 / 20$ & $587.6(20.7)$ & $4 / 14$ & $754.8(32.5)$ \\
\hline \multirow[t]{4}{*}{ Cervical DRG $\left(\mathrm{C}_{3-6}\right)$} & 32 & $0 / 8$ & N/A & $1 / 10$ & $817.0(-)$ \\
\hline & 36 & $4 / 17$ & $553.2(33.3)$ & $3 / 16$ & $722.3(8.5)$ \\
\hline & 38 & $1 / 15$ & $552.0(-)$ & $0 / 3$ & N/A \\
\hline & 40 & $1 / 9$ & $652.0(-)$ & $0 / 3$ & N/A \\
\hline \multirow[t]{3}{*}{ Trigeminal ganglion } & 36 & $0 / 14$ & N/A & $2 / 18$ & $570(70)$ \\
\hline & 38 & $3 / 13$ & $520.7(24.8)$ & $3 / 16$ & $722(55)$ \\
\hline & 40 & $4 / 14$ & $548.5(41.9)$ & $1 / 2$ & $894.0(-)$ \\
\hline
\end{tabular}

Page 6 of 12 (page number not for citation purpose) 


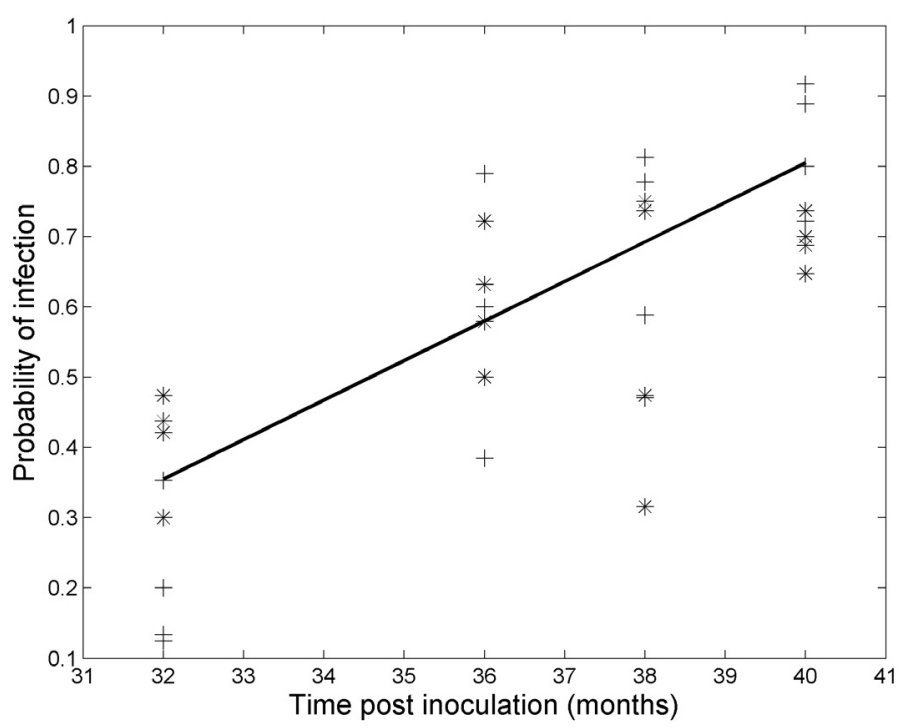

Figure 2. The predicted (solid line) versus the observed proportion of mice infected (+ RIII, * C57bl) at each time point assuming exponential growth in CNS tissues.

the estimated titre in this tissue was $10^{-1.3}$ RIII mouse i.c./i.p. $\mathrm{ID}_{50} /$ g. All other negative tissues can be considered to have a titre of infectivity less than $10^{-1.3}$ RIII mouse i.c./i.p. $\mathrm{ID}_{50} / \mathrm{g}$. For the C57bl data, it is impossible to establish the upper $95 \%$ confidence interval of the titre with any accuracy since the IP distribution is not known.

\subsection{Estimation of rate of increase of the titre of infectivity in CNS}

The estimated rate of increase of infectivity in the CNS was $0.25 \log _{10}$ mouse i.c./i.p. units per month $(95 \%$ confidence interval of 0.22 0.27 ), giving a doubling time of 1.2 months (95\% confidence interval of 1.1-1.4 months).

Assuming a mean titre of infectivity of $3.3 \log _{10}$ mouse i.c./i.p. $\mathrm{ID}_{50} / \mathrm{g}$, and given the mean incubation period for the $100 \mathrm{~g}$ dosed cattle is approximately 45 months, using the dose-response relationship estimated previously [35], this gives mean titres of infectivity of $0.1,1.1,1.6,2.1 \log _{10}$ mouse i.c./i.p. $\mathrm{ID}_{50} / \mathrm{g}$ for $32,36,38$ and 40 months p.e. respectively (and a mean of 1.23 across the 4 time points). From these titres, the predicted versus the actual proportion of mice that succumbed to BSE at each time point is given in Figure 2. The infectivity in the CNS tissues can also be expressed in terms of bovine oral $\mathrm{ID}_{50} / \mathrm{g}$ utilising results from a cattle oral attack rate study where the inoculum was of a known titre in terms of mouse i.c./i.p. $\mathrm{ID}_{50} / \mathrm{g}$ [35]; this gives mean titres of infectivity of $-2.7,-1.7,-1.2,-0.7 \log _{10}$ bovine oral $\mathrm{ID}_{50} / \mathrm{g}$ for $32,36,38$ and 40 months p.e. respectively. However, the variability of titres for a given time p.e. will be considerable since there is variability in both the incubation period distribution and the titre at clinical onset. For example, at 40 months p.e. for $100 \mathrm{~g}$ dosed cattle, simulations showed that the titre of infectivity in CNS could vary between negligible levels and an upper 97.5 percentile of $0.8 \log _{10}$ bovine oral $\mathrm{ID}_{50} / \mathrm{g}$. Lower dosed cattle will have lower titres of infectivity in CNS for a given number of months p.e. For example, cattle with a mean incubation period of $\sim 60$ months would have a mean titre of infectivity $\sim 14 \times 0.25=3.5 \log \log _{10}$ bovine oral $\mathrm{ID}_{50} / \mathrm{g}$ lower than the $100 \mathrm{~g}$ dosed cattle in this experiment for a given number of months p.e. 
Table II. Estimates of the titre of infectivity for dorsal root ganglia and distal ileum in $100 \mathrm{~g}$ orally dosed cattle at various time points post exposure.

\begin{tabular}{cccc}
\hline Tissue & $\begin{array}{c}\text { Time post exposure } \\
\text { (months) }\end{array}$ & Titre & $95 \%$ CI \\
\hline Thoracic DRG $\left(\mathrm{T}_{5-8}\right)$ & 32 & 0.38 & $(0.01,0.71)$ \\
& 36 & 0.79 & $(0.54,1.04)$ \\
& 38 & -0.30 & $(-1.42,0.3)$ \\
& 40 & 0.49 & $(0.21,0.76)$ \\
Cervical DRG $\left(\mathrm{C}_{3-6}\right)$ & 32 & -0.17 & $(-1.29,0.45)$ \\
& 36 & 0.34 & $(0.11,0.64)$ \\
& 38 & -0.18 & $(-1.1,0.39)$ \\
Distal ileum & 40 & -0.58 & $(-1.91,0.21)$ \\
& & & \\
& 6 & 1.01 & $(0.67,1.36)$ \\
& 10 & 1.10 & $(0.80,1.41)$ \\
& 14 & 1.59 & $(1.27,1.94)$ \\
& 18 & 1.58 & $(1.27,1.91)$ \\
& 36 & 0.08 & $(-1.12,0.64)$ \\
& 38 & 0.88 & $(-0.06,1.15)$ \\
& 40 & 1.29 & $(1.05,1.54)$ \\
\hline
\end{tabular}

\subsection{Infectivity in dorsal root ganglia}

The titre in the DRG was highly variable (Tab. II). A likelihood ratio test showed that there was a significant difference between the titre of the cervical and thoracic DRG; there was an 11.1 higher log-likelihood for 4 additional parameters for the model assuming different titres of infectivity between between the cervical and thoracic DRG, compared to a model assuming the same titres $(p<0.001)$. The mean titre in the thoracic DRG at the 4 time points was $0.34 \log _{10}$ mouse i.c./i.p. $\mathrm{ID}_{50} / \mathrm{g}$ (from results in Tab. II), approximately $0.5 \log _{10}$ mouse i.c./i.p. $\mathrm{ID}_{50} / \mathrm{g}$ higher than the cervical DRG, which had a mean titre of $-0.15 \log _{10}$ mouse i.c./i.p. $\mathrm{ID}_{50} / g$. The titre in the DRG was lower than CNS, with the thoracic and cervical DRG having mean titres approximately 1 and $1.5 \log _{10}$ mouse i.c./i.p. $\mathrm{ID}_{50} / \mathrm{g}$ lower than CNS respectively.

\subsection{The pattern of infectivity in distal ileum}

The titre of infectivity peaked in the distal ileum at 14 months post-inoculation, with a similar titre at 18 months (Tab. II). The titres at 36, 38 and 40 months post exposure are lower, suggesting a decline in the titre of infectivity, in contrast to experimental rodent models of scrapie where infectivity has been found to plateau in lymphoreticular tissues and the central nervous system [23]. These results for cattle correspond to the hypothesis that infectivity initially increases in the distal ileum but later decreases in conjunction with the age associated involution of lymphoid tissue in the ileum [29].

\section{DISCUSSION}

The range of doubling times for CNS infectivity presented here are lower than those assumed previously [4], which was between 2 and 4 months. Moreover the best fitting value in this study (1.2 month) was outside the previous range of values. Changes in the estimate of CNS infectivity doubling time would affect estimates of potential human food chain exposure as lower values of the doubling time result in lower infectivity levels of CNS of the cattle that evade detection. Therefore, if the results of this study were used in place of 
those of the previous estimate it would result in lower estimates of human exposure of infected cattle tissues from relaxation of the Over Thirty Months rule in Great Britain whereby all cattle over thirty months slaughtered in the UK were removed from the human food chain), than those given previously [16].

An estimate of the doubling time of infectivity in CNS has been previously produced [8], where the doubling time was inferred from the dose-incubation response curve from an oral attack rate study for BSE in cattle [35]. Using the reduction in incubation period from a 10 -fold increase in dose, it was estimated that the doubling time of infectivity for BSE in cattle was 6 weeks, which is close to the estimates provided in the present study from mouse bioassay data.

The doubling times and titres of infectivity in the CNS in this study were calculated for $100 \mathrm{~g}$ dosed cattle. Assuming that doubling times of infectivity are independent of initial dose, the results of this study allow estimation of titres according to months p.e. of lower dosed cattle by employing the incubation period distribution [35], the clinical titre distribution, and the doubling time. Such an extrapolation is very important for risk assessments of potential human exposure, since field cases would rarely, if ever, have been exposed to doses as high as $100 \mathrm{~g}$. However, it would be very useful to have verification that the rates of increase of infectivity in CNS are independent of the initial dose. Data from a recent study of the timing of detectable $\mathrm{PrP}^{\mathrm{Sc}}$ in cattle dosed orally with $1 \mathrm{~g}$ or $100 \mathrm{~g}$ of BSE affected brain tissue [1] showed clear differences between the two doses in the number of months before clinical onset that detectable $\mathrm{PrP}^{\mathrm{Sc}}$ occurred in the CNS, suggesting the possibility of differences in the rate of increase of infectivity in CNS for the different dose groups. There are tissues available from the CNS of $1 \mathrm{~g}$ dosed cattle from [1]. If funding were available, then bioassay using transgenic mice of the available CNS tissues for $1 \mathrm{~g}$ dosed cattle would help to resolve this.

It was assumed that the titres were the same in each part of the spinal cord and the caudal medulla. However, it is possible that there are small differences in titre between these tissues since probable specific routes of entry of agent to the CNS [21] suggest preferential sites for the earliest CNS replication. When the timing of first detectable $\mathrm{PrP}^{\mathrm{Sc}}$ relative to clinical onset was estimated for a range of CNS tissues in two sequential kill pathogenesis studies [1], small differences in the timing of first detection were found between CNS tissues. In particular, the rostral medulla was found to have detectable $\operatorname{PrP}^{\mathrm{Sc}} \sim 0.7$ months before the lumbar and thoracic spinal cord, which in turn were $\sim 0.2$ months in advance of initial $\mathrm{PrP}^{\mathrm{Sc}}$ detection in cervical spinal cord. Such differences in the timings of detection, if they translate into lag times for the occurrence of infectivity, would be too small to detect in the present study.

While the results presented here are for bioassay of BSE in wild type mice, the bioassay results in cattle of selected tissues from the same experimental study source [34] equate well with those assays conducted in mice, in that the more sensitive cattle assay has largely only confirmed the mouse assay results for which cattle tissues are infectious ${ }^{4}$. Indeed, assays of pooled spleens from British BSE affected cattle and a range of tissues from a terminally affected cow in Germany by inoculation of Tgbov XV mice, which overexpress the bovine PrP gene, also failed to reveal infectivity in additional tissues [3].

The results in Table II suggest that the titre of infectivity in the DRG is much lower than that of CNS. This result is important in terms of risk assessment of potential human exposure, since at the time of the OTM rule review, it was estimated that approximately $90 \%$ of the bovine oral infectious units entering the food supply was from DRG in meat [5]. For this estimate, a pessimistic assumption of the titre of infectivity in DRG was equal to that in CNS. The results of this study provide some basis to amend that assumption, and this would have a large effect on the proportion of human exposure from DRG. However, lower estimates of human

\footnotetext{
${ }^{4}$ Wells G.A.H., Hawkins S.A.C., unpublished data.
} 
exposure to bovine oral $\mathrm{ID}_{50} \mathrm{~s}$ in the food chain implies a low cattle-human species barrier [6] since there would have been less human exposure to produce the observed number of human vCJD cases.

The results for DRG for the present study are also of interest in relation to the pathogenesis of $\mathrm{BSE}$. Based on $\mathrm{PrP}^{\mathrm{Sc}}$ detection it has been suggested that DRG are only infected in concert with, or after the CNS $[1,25]$. The results here provide support for this, since the titres of infectivity were lower in DRG than spinal cord, suggesting a later timing of entry. However, although inconsistent detection of $\mathrm{PrP}^{\mathrm{Sc}}$ in DRG among animals, even after clinical onset [1], suggests that any retrograde spread from CNS to DRG might be highly variable between animals, and this variability is a likely explanation of the lack of a strong pattern of growth of infectivity in the DRG (Tab. II).

The maximum titre of infectivity in the distal ileum, occurring at 14 months, was similar to that of the CNS tissues at approximately 6 months before clinical onset (Tab. II). However, since the infectivity in distal ileum is, in all probability, confined largely to the Peyer's patches, the total load of infectivity will be lower than that of CNS, since the mass of infected tissue in the distal ileum will be far smaller than that of the CNS. Furthermore, it is possible that the incubation period to dose relationship is different for distal ileum and CNS tissues [27]. This could affect the estimates of titre for the distal ileum. A change in the dose-response curve would affect the best fitting estimates of the titre at each time point, but would not affect the observed pattern of an initial increase in distal ileum infectivity in the months immediately following exposure, followed by a decrease later in the incubation period.

This study has shown that the rate of increase of infectivity in CNS tissues is 0.25 $\log$ units of mouse i.c./i.p. ID $_{50} / g$ per month; equivalent to a doubling time of 1.2 month. It has also shown that the titre in the thoracic DRG is, on average, approximately $1 \log$ mouse i.c./i.p. $\mathrm{ID}_{50} / \mathrm{g}$ less than $\mathrm{CNS}$, and cervical DRG on average approximately 0.5 $\log$ mouse i.c./i.p. $\mathrm{ID}_{50} / \mathrm{g}$ less than thoracic DRG. The pattern of increase of infectivity in the distal ileum is that of an initial increase up to 14-18 months post exposure, followed by a decrease, which is likely to be highly variable between animals. These results will be informative for future risk assessments of BSE, especially in relation to reviewing current control measures.

Acknowledgements. The authors thank Robin Sayers and Cornelia Zekfeld of the Veterinary Laboratories Agency for assistance with the statistical analysis. They also thank John Wilesmith, Defra, for helpful comments during the preparation of the paper. They also gratefully acknowledge Dr Moira E. Bruce and Dr David M. Taylor of the former Neuropathogenesis Unit, BBSRC Institute of Animal Health, Edinburgh, for supply of mouse titration data on BSE infectivity. Funding for this study was provided by Defra.

\section{REFERENCES}

[1] Arnold M.E., Ryan J.B.M., Konold T., Simmons M.M., Spencer Y.I., Wear A., et al., Estimating the temporal relationship between $\mathrm{PrP}^{\mathrm{Sc}}$ detection and incubation period in experimental bovine spongiform encephalopathy (BSE) of cattle, J. Gen. Virol. (2007) 88:3198-3208.

[2] Beekes M., Baldauf E., Diringer H., Sequential appearance and accumulation of pathognomonic markers in the central nervous system of hamsters orally infected with scrapie, J. Gen. Virol. (1996) 77:1925-1934.

[3] Buschmann A., Groschup M.H., Highly bovine spongiform encephalopathy-sensitive transgenic mice confirm the essential restriction of infectivity to the nervous system in clinically diseased cattle, J. Infect. Dis. (2005) 192:934-942.

[4] Comer P.J., Huntly P.J., TSE risk assessments: a decision support tool, Stat. Methods Med. Res. (2003) 12:279-291.

[5] Comer P.J., Huntly P.J., Exposure of the human population to BSE infectivity over the course of the BSE epidemic in Great Britain and the impact of changes to the Over Thirty Month Rule, J. Risk Res. (2004) 7:523-543.

[6] Cooper J.D., Bird S.M., UK dietary exposure to BSE in head meat: by birth cohort and gender, J. Cancer Epidemiol. Prev. (2002) 7:71-83.

[7] Czub M., Braig H.R., Diringer H., Pathogenesis of scrapie: Study of the temporal development of clinical symptoms, of infectivity titres and scrapie-associated fibrils in brains of hamsters infected intraperitoneally, J. Gen. Virol. (1986) 67:2005-2009. 
[8] De Koeijer A.A., Heesterbeek J.A.P., Schreuder B.E.C., Oberthur R.C., Wilesmith J.W., van Roermund H., de Jong M.C.M., Quantifying BSE control by calculating the basic reproduction ratio $R_{0}$ for the infection among cattle, J. Math. Biol. (2004) 48:1-22.

[9] Dickinson A.G., Meikle M.H., Fraser H., Identification of a gene which controls the incubation period of some strains of scrapie agent in mice, J. Comp. Pathol. (1968) 78:293-299.

[10] Dickinson A.G., Meikle V.M., Fraser H.J., Genetical control of the concentration of ME7 scrapie agent in the brain of mice, J. Comp. Pathol. (1969) 79:15-22.

[11] Ducrot C., Arnold M.E., de Koeijer A.A., Heim D., Calavas D., Review on the epidemiology and dynamics of BSE, Vet. Res. (2008) 39:15 .

[12] EFSA, Quantitative assessment of the residual risk in bovine derived by-products, The EFSA Journal (2005) 307:1-135.

[13] Espinosa J.C., Morales M., Castilla J., Rogers M., Torres J.M., Progression of prion infectivity in asymptomatic cattle after oral bovine spongiform encephalopathy challenge, J. Gen. Virol. (2007) 88:1379-1383.

[14] Ferguson N.M., Donnelly C.A., Woolhouse M.E.J., Anderson R.M., The epidemiology of BSE in cattle herds in Great Britain II: model construction and analysis of transmission dynamics, Phil. Trans. R. Soc. Lond. B Biol. Sci. (1997) 352:803-838.

[15] Ferguson N.M., Donnelly C.A., Woolhouse M.E.J., Anderson R.M., Estimation of the basic reproduction number of BSE: the intensity of transmission in British cattle, Proc. Biol. Sci. (1999) 266:23-32.

[16] Ferguson N.M., Donnelly C.A., Assessment of the risk posed by bovine spongiform encephalopathy in cattle in Great Britain and the impact of potential changes to current control measures, Proc. Biol. Sci. (2003) 270:1579-1584

[17] Fraser H., Bruce M.E., Chree A., Mcconnell I., Wells G.A.H. Transmission of bovine spongiform encephalopathy and scrapie to mice, J. Gen. Virol (1992) 73:1891-1897.

[18] Ghani A.C., Ferguson N.M., Donnelly C.A., Hagenaars T.J., Anderson R.M., Epidemiological determinants of the pattern and magnitude of the vCJD epidemic in Great Britain, Proc. Biol. Sci. (1998) 265:2443-2452.

[19] Ghani A.C., Donnelly C.A., Ferguson N.M., Anderson R.M., Assessment of the prevalence of vCJD through testing tonsils and appendices for abnormal prion protein, Proc. Biol. Sci. (2000) 267:23-29.
[20] Hagenaars T.J., Ferguson N.M., Donnelly C.A., Ghani A.C., Anderson R.M., Feed-borne transmission and case clustering of BSE, Proc. R. Soc. Lond. B. (2000) 267:205-215.

[21] Hoffmann C., Ziegler U., Buschmann A., Weber A., Kupfer L., Oelschlegel A., et al., Prions spread via the autonomic nervous system from the gut to the central nervous system in cattle incubating bovine spongiform encephalopathy, J. Gen. Virol. (2007) $88: 1048-1055$

[22] Karber G., Beitrag zur kollectiven Behandung Pharmakologische Reihen versuche, Arch. Exp. Pathol. Pharmacol. (1931) 162:480-483.

[23] Kimberlin R.H., Walker C.A., Pathogenesis of experimental scrapie, In: Bock G., Marsh J. (Eds.), Novel Infectious Agents and the Central Nervous System, CIBA Foundation Symposium 135, Chichester, Wiley, 1988, pp. 37-62.

[24] Kimberlin R.H., Bovine spongiform encephalopathy and public health: some problems and solutions in assessing the risk 1996, In: Court L., Dodet B. (Eds.), 3rd International Symposium on Transmissible Subacute Spongiform Encephalopathies: Prion Diseases, Paris, Amsterdam, Elsevier, 1996, pp. 487-502.

[25] Masujin K., Matthews D., Wells G.A.H., Mohri S., Yokoyama T., Prions in the peripheral nerves of bovine spongiform encephalopathy-affected cattle, J. Gen. Virol. (2007) 88:1850-1858.

[26] Prusiner S.B., Cochran S.P., Groth D.F., Downey D.E., Bowman K.A., Martinez H.M., Measurement of the scrapie agent using an incubation time interval assay, Ann. Neurol. (1982) 11:353-358.

[27] Robinson M.M., Cheevers W.P., Burger D., Gorham J.R., Organ-specific modification of the doseresponse relationship of scrapie infectivity, J. Infect. Dis. (1990) 161:783-786.

[28] Taylor D.M., Fraser H., McConnell I., Brown D.A., Brown K.L., Lamza K.A., Smith G.R., Decontamination studies with the agents of bovine spongiform encephalopathy and scrapie, Arch. Virol. (1994) 139:313-326.

[29] Terry L.A., Marsh S., Ryder S.J., Hawkins S.A.C., Wells G.A.H., Spencer Y.I., Detection of diseasespecific PrP in Peyer's patches of the distal ileum of cattle orally exposed to the BSE agent, Vet. Rec. (2003) 152:387-392.

[30] Wells G.A.H., Dawson M., Hawkins S.A.C., Green R.B., Dexter I., Francis M.E., et al., Infectivity in the ileum of cattle challenged orally with bovine spongiform encephalopathy, Vet. Rec. (1994) 135:40-41. 
[31] Wells G.A.H., Dawson M., Hawkins S.A.C., Austin A.R., Green R.B., Dexter I., et al., Preliminary Observations on the pathogenesis of experimental bovine spongiform encephalopathy, In: Gibbs C.J (Ed.), Bovine spongiform encephalopathy: The BSE Dilemma, New York, Serona Symposia, Norwell, USA Springer-Verlag, 1996, pp. 28-44.

[32] Wells G.A.H., Hawkins S.A.C., Green R.B., Austin A.R., Dexter I., Spencer Y.I., et al., Preliminary observations on the pathogenesis of experimental bovine spongiform encephalopathy (BSE) - An update, Vet. Rec. (1998) 142:103-106.

[33] Wells G.A.H., Hawkins S.A.C., Green R.B., Spencer Y.I., Dexter I., Dawson M., Limited detection of sternal bone marrow infectivity in the clinical phase of experimental bovine spongiform encephalopathy (BSE), Vet. Rec. (1999) 144:292-294.

[34] Wells G.A.H., Spiropoulos J., Hawkins S.A.C., Ryder S.J., Pathogenesis of experimental bovine spongiform encephalopathy (BSE): pre-clinical infectivity in tonsil and observations on lingual tonsil in slaughtered cattle, Vet. Rec. (2005) 156:401-407.

[35] Wells G.A.H., Konold T., Arnold M.E., Austin A.R., Hawkins S.A.C., Stack M., et al., Bovine spongiform encephalopathy: the effect of oral exposure dose on attack rate and incubation period in cattle, J. Gen. Virol. (2007) 88:1363-1373. 